\title{
Empirical and Phenomenological Studies of Embodied Cognition
}

David Morris, Department of Philosophy, Concordia University, davimorr@alcor.concordia.ca

Final draft of an chapter published in The Handbook of Phenomenology and Cognitive Science, eds. Shaun

Gallagher and Daniel Schmicking (Springer Verlag: 2010), pp 235-252.

The first grand wave of twentieth century cognitive science and philosophy of mind sought and still seeks to show how, contra Cartesian dualism, cognition is materialized in the brain. A new wave is rising from this, though, one that studies cognition not merely as "embrained" (Damasio 2000, 118; Collins 2000) but as embodied in a much stronger sense, as inseparable from and shaped by the concrete extra-cerebral structures and dynamics of the body, and the body's embeddedness in the natural and social world. This wave is gathering momentum. Whereas a decade ago researchers needed to protest that cognition is in fact strongly embodied, one can now find studies that leap right to the problem of how and in what sense it is so. This is a telltale sign of a nascent paradigm shift. Yet, in studying this new wave one finds that philosophy and science are still—for reasons recently remarked (see Dreyfus 2007; Gallagher 2007) and soon discussed-at sea for lack of conceptual frameworks to bring embodied cognition back to firm land. Brooks, whose robotics research is part of the new wave, puts it succinctly: "perhaps at this point we simply do not get it, and there is some fundamental change necessary in our thinking." (1991; cited in Dreyfus 2007, 251)

Since the study of embodied cognition surges with deeply conceptual problems and is in the midst of a sea change, this chapter cannot simply summarize fully worked out results. It is inevitably synthetic. Given the handbook's overarching goal, my aim is to show how an older wave of philosophy - the phenomenological tradition initiated by Husserl—can, on the conceptual level, complement new wave empirical results in cognitive science.
Phenomenology is well positioned for this complementary role. If philosophy in general is in the business of creating or analyzing the concepts we deploy in our everyday and scientific labours, phenomenology's distinctive task is to have rigorous description of the phenomena drive philosophy's conceptual endeavour. And whereas science normally fits empirical data into existing conceptual frameworks, shifting paradigms only in moments of crisis, phenomenology begins with a principled conceptual crisis-the reduction - that puts our most basic concepts into question. The reduction is never left behind and it radically shifts paradigms all the way down. But it shifts paradigms by holding itself responsible to what empirically presents itself. So, as Russon (2006, 308) notes, phenomenology is a form of empiricism in which we "let our (rigorously enacted) observations specify the terms and parameters of our theories, rather than holding description answerable to theory." Phenomenological and empirical studies of embodied cognition can therefore mutually constrain or enlighten one another in ways that let phenomenologically inspired researchers contribute to new wave research. (See, e.g., Varela 1996; 1999; Gallagher 1997, 2005; Thompson 2007; also see Schmicking in this volume Petit 2003; Borrett, Kelly, and Kwan 2000). But, given the nature of the conceptual problem that is outlined below, instead of pursuing this strategy of mutual constraint, I lean more heavily on phenomenology's basic conceptual results, whilst keeping phenomenology in conversation with empirical studies.

The next section develops the conceptual problem by introducing and 
explaining the strong thesis that cognition is embodied and outlining the

phenomenological view of it.

\section{Empirical Studies of Embodied Cognition and the Spectres of Crypto-Cartesianism}

What could it mean to challenge traditionally neurocentric views by making the strong claim that cognition is 'embodied over and above being embrained', by claiming, for example, that the hands have some role in cognition? And why would one ever say such a thing? One reason is to exorcise hidden, crypto-Cartesian ${ }^{1}$ conceptual prejudices about body and mind that do not fit the empirical evidence and consequently hobble traditional approaches. As shown below, empirical studies pressure science into discarding traditional concepts of the body as inadequate in accounting even for walking, an obviously embodied activity. So we should be all the more suspicious of deploying such concepts in trying to unify body and mind. But we will see that even as we try to escape these problematic concepts our tradition tangles us in further cryptoCartesian prejudices-which is why we should turn to phenomenology as deriving results on a different conceptual level.

Empirical studies give evidence that human walking is controlled not by neurology alone but is shaped by legenvironment dynamics (Thelen 1984, 1995; Thelen and Smith 1994) and even social factors (cf. Zelazo 1983, 1984; Fogel 1993). Further, there is evidence that muscular synergies crucial to limb control are not specified by fixed anatomical structures but by "soft assembled," dynamic, environmentally modulated functions (Turvey 2007). Studies of biped, quadruped, and hexapod animals show that their gait pattern is best explained in terms of structured leg dynamics inherited through evolution, rather than central neural controllers (Full and Farley 2000). Robots that control walking through central processors cannot handle shifting terrain and require far more energy and actuator precision than are found in humans. These problems can be tempered by leveraging the dynamic morphology of leg joints, and of the body as linking legs together, for control. (Brooks 1991; Collins et al. 2005) Simulations show that body symmetry (vs. asymmetry) facilitates control of locomotion and increases locomotory efficiency (Bongard and Paul 2000).

While traditional accounts conceptualize limb control as a problem solved by the brain, the empirical studies show that the dynamic body is itself integral to control. Where traditional accounts thinly conceive the brain as a computational device (whether serial, parallel, or neural/distributed), the new wave thickens this by showing how the body itself is integral to the brain's controlling 'computations'. The mind not only extends into notepads, etc., that do cognitive work (as Clark and Chalmers (1998) argue), it extends into limbs that do work in their own control. The traditional, thin concept of the body as a dumb machine is thereby also thickened, because the body itself, in virtue of its dynamic morphology, has a kind of 'know how' or “cleverness” (Csepregi 2006).

Embodiment thus matters over and above embrainment - embodiment does cognitive work. To put it more sharply: The body is not a passive puppet moved by the brain as sole controlling agency. The body (with its brain) is a controlling agency.

Were we to extend this thesis to cognition in general we would say: the body is a cognizing agency. In this case the infamous "brain in a vat" (conjured to show, contra Cartesianism, how cognition can be embodied by way of being embrained) 
would be a misguided, vatic abstraction. More, it would in fact be disembodied, for it lacks the right kind of body to do thinking, namely the moving body so vital to kinetic coping and evolution. (See Sheets-Johnstone 1999, 1990) But can we extend this thesis to cognition, which is after all, our topic? An objector will surely say that the above data, while convincing in showing embodiment's importance to actions such as walking, has no bearing on cognition proper.

In reply, we must first of all emphasize that walking is not merely limb movement, but intelligent interaction with the environment. So points about walking are already points about a discerning, judging, cognitive activity. But such activity has its roots in the body. For example, the complex locomotory response of cockroaches blasted with compressed air is too quick to be explained by nerves and is instead rooted in viscoelastic musculoskeletal structures (Dickinson et al. 2000, 103). The structure of the cricket body and ear, over and above neurology, is integral to its orienting to the chirps of other crickets. (Clark 2001, 127-8) Sheet-Johnstone (1999; 2003) shows in detail how bodily, animate movement already is intelligence. The body itself is a mindful responder. Perhaps neurology merely complicates the already supple adaptive richness of bodily responses (see Wheeler 2005, 134, 195-211).

Besides, the objection is premised on sharply dividing action, perceptual cognition and 'higher order' cognition from one another, so as to rule out drawing conclusions from one domain into the others. But thinkers as diverse as Dewey (1972), Merleau-Ponty (1962), Varela (1991; 1993), Hurley (1998), Berthoz (2000), O’Regan and Noë (O'Regan and Noë 2001, 2001; Noë 2004), Wheeler (2005), Thompson (2007), and Turvey $(2007,663)$ argue that the traditional actionperception-cognition distinction is conceptually and/or empirically misguided. As Gallagher $(2005,136)$ insists, "[p]erceptual experience is generally accepted to be fundamental to other modes of cognition and action.”

This point is amply confirmed by empirical evidence that action, perception, and embodiment mix in shaping 'higher' cognition. Just some of this evidence will now be mentioned. For example, psychologists show that walking is integral to the infant's cognitive development (Kermoian and Campos 1988; Fogel 1993; Thelen 2000). Tactile cognition is shaped by movements, skills and habits of touching (Katz 1989; Lederman and Klatzky 1987). Similarly, visual cognition is shaped by looking (Merleau-Ponty 1962; Churchland, Ramachandran, and Sejnowski 1994; O'Regan and Noë 2001; Thompson 2007). Rhythms of the moving body influence our hearing metrically ambiguous six beat musical rhythms as being either in three groups of two beats, or two groups of three beats. (Philips-Silver and Trainor 2007)

On the level of language and thinking, studies show that sentence formation is not wholly governed by abstract syntax but is influenced by bodily speech rhythms alien to vatic embrainment (Lee and Gibbons 2007) and that body language is integral to thought and language, rather than being a merely external accompaniment (McNeill 1992). Gesture also facilitates human learning. Specifically, in learning, bodily gestures that are initially topologically isomorphic to a learning domain are metonymically shortened in ways that give rise to more abstract typological symbols that facilitate the learning of abstract concepts. (E.g., gestures mimicking atomic attraction contract into shorthand symbols for atomic bonds.) (Roth and Lawless 2002) Chimpanzee manipulation of what Clark (2006, 294) calls "material symbols" suggests that such symbols can facilitate 
high order cognition, for example, they facilitate chimpanzee judgement that the relations of difference and sameness are different relations. Together these points might suggest that the gestural body itself is a material symbol whose flexibility is integral to cognition - that we learn not by abstract symbol manipulation but by way of generating new symbols through our body's manipulation of things. This is a point well anticipated by Merleau-Ponty (1962) in his studies of expression and helpful in addressing the notorious symbol grounding problem (see, e.g., Thompson 1997).

It also resonates with Lakoff and Johnson's analyses of how our thinking and imaging is organized by schemata rooted in bodily ways of doing things. For example, the schema of something moving from a source, along a path, to a goal-a schema initially grasped on a bodily levelunderlies metaphors in multiple cognitive domains (e.g., "I am trying to reach the end of this chapter”). (Lakoff and Johnson 1999; Johnson 1987, 2007; also see Gibbs and Berg 2000) Similar phenomena suggest that the roots of thinking (Sheets-Johnstone 1990) and even mathematics (Lakoff and Núñez 2000) are in the moving body. Data on mental imagery tasks (such as watching a moving object and reporting its final position from memory) further suggest that imaging involves a kind of internal gesture or material symbol manipulation rooted in our bodily relation to things (versus an abstract symbol transformation). (Gibbs 2006; Gibbs and Berg 2000; Amorim and Isableu 2006) Researchers have also demonstrated what should probably be called the Proust effect: recall of biographical episodes is faster when body position during recall is congruent (vs. incongruent) with body position during the original episode. (Djikstra, Kaschak, and Zwaan 2007; cf. Casey 2000; SheetsJohnstone 2003)
Over and above the brain, the morphology, dynamics and temporality of the body, and our evolved, moving attitude to the environment, shape and lurk in our acting, perceiving, speaking, learning, remembering, and conceptualizing. This link between the body and cognition is supported in recent neurological literature, which shows that 'higher' cognitive processes (involving activation of 'higher' brain structures) in fact also activate and are activated by 'lower' brain structures known to be active in emotional affect, in proprioreceptive and visceral processes, and in body control. As Tucker puts it, it "may be that there are no brain parts for cognition, at least not separate from the brain mechanisms pertaining to bodily functions." (Tucker 2007, 14; also see Damasio 1999; 2000; 2003; Freeman 1999; Gallagher 2005; Berthoz 2006; Thompson 2007) All of this, plus the observation that-as William James (1950, 138; cf. Sheets-Johnstone 1999, ch. 10) notes - the brain evolved as an organ of action at one with the body, make it empirically implausible to think that there would be anything like human thinking in a vat other than our body, or that thinking in general is a purely embrained matter. Tragic evidence for these points is given by the closest thing we have to empirical studies of brains in vats, namely notorious studies at McGill university by Ewen Cameron and Donald Hebb (see Kubzansky 1961) of people deprived of sensory stimulation and self-movement. On the Cartesian or embrainment view, an immobilized mind would simply have nothing much to think about. But people who are deprived of 'embodiment over embrainment' lose their minds - their thinking is severely disturbed, implying that the mind is deeply mobile and bodily.

To review the above, by way of condensing and elaborating Wilson's (2002, 626 ) identification of six views of embodied 
cognition: 1) Cognition is situated in a realworld environment and inherently mixes perception and action. 2) Cognition is responsive to real-time demands and operates through the real-time dynamics and rhythms of the body (vs. being a rate-independent computational process). 3) The environment and the body do cognitive work, and 4) are part of cognition. 5) Cognition is for action. 6) Even 'off-line' activities such as remembering, imagining and abstract thinking have bodily roots. Cognition, in other words, is physically grounded (see Anderson 2007), in the sense that the physical specificities, rhythms, dynamics and shape of the moving body, and its embeddedness in the world and social settings, matter to cognition in a full-fledged way (versus it being the case that only basic physics matters to cognition, in realizing a wetware computer or connectionist pattern recognizer).

New wave researchers endorse the above claims in various mixtures. The strong version of embodied cognition pursued here would endorse all of them. To briefly voice such claims through the work of important phenomenologically influenced researchers, Sheets-Johnstone (1999) argues that taking evolution and the phenomena seriously means realizing that:

At their most fundamental level, subjective experiences are tactilekinesthetic experiences. They are experiences of one's own body and body movement; they are experiences of animate form. These experiences are the bedrock of thinking. (435)

As Gallagher (2005) puts it, the "body actively organizes its sense experience and its movement in relation to pragmatic concerns" (142) — the body is no mere passive receptor-and "a full picture of human cognition can be drawn only by exposing the details” of this (133).
Dreyfus (1992; 2002; 1998; 2007; Wrathall and Malpas 2000) approaches this issue by emphasizing that bodily, skillful coping is no mere accompaniment to cognition but is itself cognition. In Thompson's (2007, 256) words, "[s]ensory stimulation does not cause experience in us, which in turn causes our behaviour,” rather (citing O’Regan and Noë) “"skillful activity...is the experience."” Noë (2004) details how bodily action is internal to perception and shapes consciousness, concluding that a plausible account of consciousness "must be an account of [it] as a natural phenomenon” (vs. an abstract computational phenomenon) and this "will be a tale, not about the brain, but about our active lives.” (231) Thompson $(2007,128)$ strikes a deeper conceptual chord by arguing for an underlying "deep continuity of life and mind," such that "life and mind share a basic set of organizational properties, and organizational properties distinctive of mind are an enriched version of those fundamental to life." In other words, the phenomena drive these thinkers to conceive mind as a process rooted in evolution and development (both individual and social). Mind leverages what already belongs to life and to skillfully moving, organized bodies. As Johnson (2007, 279) writes:

The human mind is not contained in the body, but emerges from and coevolves with the body....A human being is a body-mind, that is, an organic, continually developing process of events.

Why are these claims so new-wave, controversial or hard to grasp? Conceptual issues are unavoidable here, for noticing the empirical phenomena catalogued above is not yet the same as having these phenomena count as evidence for strong (or even weak) versions of the embodied cognition thesis. One can easily conceptualize the phenomena so as to stick with old-wave embrained views. For example, evidence shows that 
emotional affect is integral to our ability to make cognitive judgements (e.g., to decide which of two projects to pursue). This is what leads Damasio (1999; 2000; 2003) to urge 'embodiment over embrainment'. But as Gallagher $(2005,135)$ points out, in actual detail Damasio deflates the body to its representation in the brain (or inflates it to ideas of the body). For Damasio, the body is important-but only as embrained. Data of embodiment is muddled into data of embrainment without even noticing it. Likely we can always (whether deliberately or unthinkingly) muddle the data this way. For example, physically grounded body rhythms can be muddled into relations between neural time-stamps registering bodily events. What tells us to stick with the strong embodiment thesis and what helps us pursue it without muddling cannot be mere data but conceptual frameworks and desiderata.

But our navigation of this conceptual level is swamped by crypto-Cartesian prejudices that run so deep as to distort our account of the body, never mind mindwhich is why I began with studies of walking. These prejudices keep rising from the crypts of our tradition, like conceptual vampires that suck the life from cognition. Even as we nail Cartesian substance dualism into the coffin of dead ideas, it shape-shifts into a new dualism of brain and body. Even as we exorcise the Cartesian concept of mind, we retain an essentially Cartesian concept of the body as dumb machine (see Merleau-Ponty 1962, 1965; Burwood, Gilbert, and Lennon 1999), and thence a dualism between the body as living agency and the body as passive machine (see Thompson 2007, 230-237; Leder 1992)_all of which betray bodily phenomena. Indeed, Wheeler (2005, ch. 2-3) catalogues eight crypto-Cartesian prejudices, tracing their cross-linked origins in Cartesianism and their persistence in philosophy and science.
Most are converse to the claims of embodied cognition treated above, but it is worth noting the prejudices of explaining cognition in terms of (1) subject-object dualisms, (2) representations (that repair the subjectobject dualism) and their transformations, (3) temporally austere terms (such that, e.g., physically grounded real-time rhythms muddle into rate-independent relations between representations); (4) and explaining intelligence as the outcome of general purpose reasoning (vs. reasoning specific to a creature's evolution).

To pursue the embodied cognition thesis we must shed these crypto-Cartesian conceptual habits and see the phenomena anew. But here a deeply subtle point comes into play. Old-wave research conceptualizes embodiment as a solution to the problem of how mind fits with matter. Conceptually, the problem is how the phenomenon of mind, which can be coherently described in terms independent of the body, is materialized. It is answered by appeal to properties of the body, which likewise can be coherently described as independent of mind. Old-wave philosophy and science accept this framing of the problem but endeavour to resolve it by showing how the descriptive differences can be bridged. Crucially, this formulation of the problem remains essentially Cartesian and dualist in character. It is no wonder that efforts to resolve it lapse into cryptoCartesian prejudices or retain residual dualisms. (The embrainment thesis in effect acknowledges that if body and mind are descriptively dualised, then the solution requires a special body part (the brain as, e.g., symbol processor) capable of doing something most unbodylike.)

Phenomenology radically reframes the problem, indeed it shows that the old problem is badly put. To anticipate, phenomenological description shows that the mind is an inherently temporal process, that cognitive contents are not given all at 
once, but take time. But the mind does not supply or regulate this time. The mind is rather its exposure to a time that exceeds it. Husserl finds that this exposure has the form of kinaestheses, felt bodily movements. ${ }^{2}$ This is why Thompson can insist that skillful activity is not the cause of experience, but "is the experience": the 'stuff' of experience is time-and time is felt in movement. Along these lines, the strategy of the next section is to show that mind is body by showing that the time of thinking is the time of bodily moving. The section after that conversely suggests that body is mind by showing that the time of bodily moving is not the time of a clockwork machine, but of cognizing. We typically fail to grasp these points and find the strong embodied cognition thesis controversial because (as the next section suggests) we prejudicially remove body and mind from time, reducing them to things completely present and given, e.g., to Cartesian substances or computational or bio-mechanical systems. And we also prejudicially tend to reduce time itself to an already given dimension. By drawing on the theme of time, the following sections are meant to give an example of the sorts of arguments, conceptual frameworks and resources that phenomenology can offer to complement recent empirical results on embodiment. They also give an example of phenomenology's strategy and approach to mind and body.

\section{Mind is Body: Movement, Time and the Prejudice of Presence}

I develop a phenomenological argument that mind is body by linking Husserl's Cartesian Meditations (CM, 1991) with his lesser known emphasis on kinaesthesis. ${ }^{3} C M$ begins by endorsing Descartes's argument that philosophy, for methodological reasons, must begin with the "I think." But Husserl argues that Descartes muddles his beginning by prejudging what the "I think" is. So Husserl sets out to rigorously describe the phenomenon of thinking. He ultimately finds that the "I think" is already a kinaesthetic "I can.” In other words, phenomena of mind, rigorously described in their own terms, must already be conceptualized as bodily phenomena.

How does Husserl arrive at this point and what does it mean? One of Husserl's fundamental insights is that cognitive phenomena always have a horizonal character (see esp. $C M \S 19$ ).

Phenomenological description shows that in perceptual experience cognitive objects (noemata) are not given all at once. To perceive a die is not to have it presented or represented as an entirety in a cognitive instant. Each actually appearing die-face has its sense as a real die-face only through its relation to other actually appearing faces and through their portending of hidden faces, it has its sense in the way that one die face leads to another. Hidden faces are only potentially apparent, but in turning the die they can become actually apparent. The sense of the real die as a whole is thus not something entirely present, but an invariant pattern of an (in principle) unending unfolding of actual and potential perceptual profiles of the die. The structure of ““"predelineated” potentialities” through which such a thing unfolds is what Husserl calls a horizon. (CM 82) Horizons are dynamic (the die's predelineated potentialities change as one turns it) and complexly nested (the sense of the die's six-face lies in its dots as horizonally portending each other).

The above point is about noematic horizons - the horizons of objects of cognition. But Husserl shows that each act of cognition (noesis) also has an horizon-a noetic horizon. The cognitive act of perceiving this-here real die has its sense in 
further acts that ongoingly fulfill the initial act's sense (the sense "die" is in the act of seeing the six-face turning into the act of seeing the two-face). So a cognitive act "is never present to actual consciousness as a finished datum; it becomes "clarified” only through explication of the given horizon and the new horizons continuously awakened.” (CM 82-83) Both noetic acts and noematic objects take time.

Already the above means that perceptual cognition is of itself bodily. First, as Thompson (2007, 248) observes, following Husserl and Merleau-Ponty (1962; 1964), the fact that perceptual consciousness always unfolds in correlation with unfolding object profiles means that objects and cognitive acts themselves mark perception as endogenously spatial and perspectivalwhich "requires that we be embodied," have a bodily place from which we perceive. Second, as Landgrebe (1973) emphasizes, according to Husserl, each experience, as having its sense in a horizonal "indication of possibilities,” has the form of: “"I can continue and will presumably gain this or that new impression from the thing."” (10) That is, experience is not just perspectival: it involves spatial perspectives changing over time. Moreover, horizonal possibilities of change are not represented in some sort of completed roster, rather I am aware "of them as that which is not yet actual but that can take place precisely because I can bring it about.” (10, my emphasis) But according to Husserl, the "I can" here is bodily: the protentive promises of the die's faces, in which rests the very sense "die," is confirmed or disconfirmed in kinaestheses, movements initiated and felt in experiencing the die. (8) So "[p]erception is impossible without the experience we gain in kinaesthetic movement.” (11) The phenomenological evidence shows that the Cartesian "I think," as taking time, must already be preceded by an "I can" and an "I move." The fifth meditation of $C M$ emphasizes that this in virtue of what Husserl conceptualizes as Leib, the lived body (also translated as "animate organism”). The Leib is the body felt and lived in the "I can move," a body that is inalienably my own. Leib contrasts with Körper, a term designating the body as an object studied, say, by the doctor. ${ }^{4}$ The "I think" is in and of itself already bodily, for thinking is determinate only by way of temporally opening to further possibilities that exceed presence-and this is by way of the moving Leib. (See also Husserl 1989, §59-60; Sheets-Johnstone 1999, 1999, 1999, 131-140; Zahavi 1994, 2003, 98-109; cf. Gallagher 1986)

It is worth reflecting here on the root of Husserl's divergence from Descartes. In the second meditation Descartes notoriously argues that I see the wax not with my eyes but with my mind. Extraordinarily, Descartes's argument, which concludes by splitting the "I think" from the bodily "I can,” is driven by the very same horizonal phenomena that drive Husserl to the opposite conclusion. For Descartes, the wax is so excessively horizonal that not even the imagination could exhaustively determine its identity. This requires an "idea," which alone can determinately comprehend all variations of the wax for all time. Seeing the wax is therefore an act of judgement that subsumes phenomena (that are in principle indeterminate) to an idea (that is in principle fully determinate). The body could never pull off such an act because its very time of being is an opening to always excessive indeterminacies_-bodily time inherently invites doubt. So if a Cartesian idea is to escape indeterminacy and doubt, it must clinch its object via a representational relation. This representational relation is highly problematic. By virtue of the very problem an idea is meant to solve, an idea must have a fully determinate content that 
subsumes or intends something indeterminate. So an idea must subsume something entirely unlike an idea. Dualism is thus foreshadowed in the very notion of an idea.

What is going on here? Faced with the phenomenon of horizons as threatening the foundations of determinate knowledge, Descartes reaches to ideas as something that would be fully determinate in face of indeterminacy. But the phenomena give no evidence of fully determinate entities. Objects are certainly not given to us as fully determinate. If they were, there would be no doubt and no need for philosophy. And the phenomena show Husserl that cognitive acts are also not wholly determinate but horizonal. Likely, Descartes bypasses the indeterminacy of the phenomena because of a prejudice that runs deep in all our philosophy and thinking: the prejudice of presence, which motivates his appeal to a cognitive content—an idea-that would be entirely present, given and determinate all at once, that would subsume the indeterminacy of changing time to the timeless determinacy of unchanging essences.

For Husserl, Descartes's problem is the solution: the very indeterminateness of the horizon, which yet has "a determinate structure” (CM 83) that cannot, however, be reduced to presence, is what carries the sense that Cartesian ideas would determine as all present. Brooks (1991) insightfully moots the problem that robots run into when we engineer them to navigate by fully representing the determinacies of an environment that is in fact inexhaustible and ever changing: he suggests that the environment be used as is its own 'representation'. Husserl similarly moots the Cartesian problem that the phenomena are inherently indeterminate and thence exceed us: he notes that the phenomena in their very temporal indeterminacy are the very determinacy needed for knowledge. (As
Husserl puts it, "The [horizonal] predelineation itself, to be sure, is at all times imperfect; yet, with its indeterminateness, it has a determinate structure.” (CM 83)) Indeed, if phenomena were wholly present and determinate, then truth and verification would have no sense. As Merleau-Ponty $(1962,204)$ would note, the six faces of a real die cannot all be present to us in the same way at once; the reality of die lies in the way it keeps on temporally turning up new faces and hiding other ones from us.

In other words, on its deepest register, all the crypto-Cartesian prejudices discussed above in turn presume the prejudice of presence: the prejudice that being and beings, whether thingly or cognitive, are, ontologically speaking, given all at once as fully there. To undo this prejudice we must, like Brooks and others discussed above, conceive cognitive processes as assembling themselves in real-time by way of being bodily processes movingly embedded in worlds and times that exceed them. But this conceptual move is easy to muddle, and we can now say why: to stick with it we have to overcome the prejudice of presence and our related tendency to think that explanation is satisfactory only if it comes to a stop with something that is all there at once (which also means that we tend to explain temporal processes by making time into something that is all there).

For example, Lloyd (2004; cf. Varela 1999), who is inspired by Husserl's emphasis on cognition's inherent temporality, notes our tendency to render cognitive states as being entirely present in the brain areas that 'light up' in fMRI imagery. He also notes that we forget that fMRI averages brain activity over time such that it blurs changes on the rapid time scale of thinking. In reducing cognition to fully determinate activations we prejudicially neglect the way cognition might actually be 
a matter of rapid micro-temporal rhythms of change, kin to horizons of neural activity enacted in concert with bodily horizons. In this context the objection that kinaestheses and Leib can (for the brain in the vat) be simulated mistakenly reduces these to presence by abstracting them from the realtime demands that drive our brainy-body evolution, in the way that real rhythm is ruined by reducing it to ratios. But our technology and conceptual frameworks likewise tend to mistakenly envat the real brain in a frozen present. Notably, the embodied cognition thesis can always be refuted by way of reducing its terms to presence. Ultimately the only thing that testifies against this reduction is the being of the phenomenon itself in its own time. But that is precisely what the prejudice of presence freezes out of the picture.

Here we must address another objection. The above may convincingly show that perceptual cognition, perhaps even imagining and dreaming, are already bodily. Surely, though, this analysis does not go through with abstract cognition! But let us look at a doctor. As her patient walks through the door, her head cocks to listen for shuffling feet that betray neurological problems, her nostrils sniff for breath odours symptomatic of metabolic problems; later she taps tympanically on the patient's torso, listening for inner organ problems. The doctor experiences her diagnostic reasoning unfolding in these kinaestheses. If medical reasoning could be abstracted from bodily kinaestheses, then likely it would not be fraught with the stupendous errors and prejudices that Groopman (2007) catalogues. Later, when writing up her report, she feels her reasoning operating in the hesitation of her pen and body, which hesitation is her way of thinking that: "But maybe this logical option is not the case." (See Johnson 2007, ch. 3) Scientific reasoning, too, proceeds through kinaesthetic engagement with images and apparatus (see Galison 1997), and the process of writing things up and conversing about them.

Our earlier point that noetic activity is horizonal indicates a deeper phenomeno-logic behind these last points. If my thought "triangle" did not or could not actually temporally lead through its horizon to the thought that its angles sum to $180^{\circ}$ and so on (and to noematic objects verifying these), then I would either doubt that I am really thinking "triangle," or think that I am changing its ideal sense (by thinking, say, of spherical triangles). The sense of even ideal objects lies in the fulfilment of their horizon potentials. But for me as human, not divine, fulfilling these horizons takes bodily doing and time. If you put me into a sensory deprivation tank or a 1984-like polity that perverts all recording and communication, then I shall go mad, for I shall lose track of the sense of my own thinking. As Husserl argues in his later Crisis of the European Sciences (1970) and "The Origin of Geometry" (available in Merleau-Ponty 2002), community, history, "writing down," and moving one's Leib in a shared life-world are crucial to abstract ideas and thinking, a point amplified in the cogito chapter of Merleau-Ponty's Phenomenology of Perception (1962; also see Merleau-Ponty 2002). From this perspective, the Cartesian "evil genius," who could even make us doubt that $2+2=4$, is not an all powerful mind but... disembodiment itself. To put the brain in any 'vat' other than the body is to subject thinking to such ineradicable doubt that it is driven mad or mistakes itself for an all knowing divine. In contrast, the mind conceptualized as Leib is itself open to endless temporal horizons that at once account for doubt (without which we could not be philosophers) and for its resolution via kinaesthetic, intersubjective explorations 
and recordings (without which we could not be scientists).

As Husserl compactly puts it, in one of the most pungent sentences of CM: “Objects exist for me, and are for me what they are, only as objects of actual and possible consciousness.” (99) But, as Husserl immediately insists, we need to give a concrete account of this possibility and actuality. In doing so we find that the kinaestheses of the Leib, as the kernel site of actuality and possibility, are indispensable to all objects-including abstract ones - such that, as Gallagher (2005, 1-5, 133-8) might put it, prenoetic bodily processes are prelude and postlude to each noesis. The mind is not so much given in the head, yet subsequently extended into things, as Clark and Chalmers (1998) have it. The mind is its extension in living moving bodies, its opening in time.

Aside from his discovery of horizons, one of Husserl's other great discoveries is intentionality: that all consciousness is consciousness of something, that consciousness is of itself a relation to a content. For the tradition we are criticizing, the phenomenon of intentionality is a great problem that repeats the Cartesian problem of ideas: how can a subjective representation be intentionally related to an outside object wholly unlike it? What we are in effect learning is that intentionality is in fact the solution to the Cartesian problem-once we understand that intentionality is bodily and inherently temporal, rather than being the presence of a (fully present) cognitive state to an external object.

On this analysis, the phenomenological labours of Heidegger and Merleau-Ponty are (merely) crucial inflections of Husserl.

Merleau-Ponty (1962) deepens the point that intentionality is inherently bodily, through his well known discussion of the intentional arc, Leib and bodily habits and movement. (See Barbaras 1992, 2003; Gallagher 1995, 1986, 1986; Gallagher and Marcel 1999;
Dreyfus 2002; Leder 1992, 1990)

Heidegger's Being and Time (1962) expands Husserl's treatment of the moving body by showing, in effect, that the sphere of the moving Leib is in fact the complete sphere of interpretation that is our intersubjective world: the prenoetic body is in fact prenoetic human reality. (Cf. Dreyfus 1992, 1991; Dreyfus and Hall 1982; Olafson 1987) And Being and Time further shows how the proper conception of human reality entails overturning the prejudice of presence and temporally austerity. It requires thinking of being as time-and not reducing time to a present dimension.

The conceptual points articulated here by way of phenomenology complement the ones articulated earlier via empirical study. But phenomenology presents a strategic and methodological advantage in drawing its point directly from the phenomenon of thinking and flagging deep conceptual prejudices that we will have to undo if we are not to muddle our study of embodied cognition.

\section{Body is Mind: Bringing the Zombie to Leib}

Above we saw that the phenomenon of mind, when rigorously described, is not something wholly present to itself but is an open temporal transcendence that exceeds itself. This is to say that mind is body, for the term "body" simply designates and describes the phenomenon in which this temporally open self-transcendence is figured and takes place. (Cf. Russon 2006) And so we can better grasp the claim that mind is body by better grasping how the body, as this temporally open selftranscendence, is thus already mind. I do this by briefly indicating three phenomenological arguments.

First, I pursue a point on the cusp of our intertwined claims that mind is body and 
body is mind. Once we abandon the prejudice of presence and turn to a temporally rich phenomenology of mind, we find (as Husserl showed in detail) that memory is crucial to mind, both as primary memory (which implicitly retains the unfolding present so that, e.g., we can hear a note as following the previous one) and as secondary memory (which explicitly recalls episodes of the distant past). But as Casey (2000), Sheets-Johnston (2003) and Russon (2003) observe, memory is not strictly speaking 'in the head': it is in our body and the places we inhabit. The body in its kinaesthetic engagement with places and markers is a well of memory integral to mind - the body in the world is itself the first "writing down." Correlatively this suggests that one's body already works as memorial mind.

Second, the thought that the human body is merely a dumb, mindless Cartesian machine is just the thought that the concept of a "zombie" is coherent. In philosophy of mind a zombie is (the equally fictional and unempirical) counterpart of the brain-in-thevat: a body without a mind for a mind without a body, a creature who looks and acts just like you and me but is not in fact thinking or experiencing. Thompson (2007, 232) subjects this concept to a devastating critique via Husserl. Basically, if perception and perceptual behaviour have horizonal structures - and they must, given the phenomenon of perception - they entail experience of bodily kinaestheses, that is, awareness and anticipation of one's bodily kinaestheses. So if zombies are behaviourally indistinguishable from humans perceiving things, they must be experiencing, kinaesthetic bodies. So the zombie-body must be a Leib, not a Körper. The zombie who behaviourally treats the die as real must have a feel for the die turning in hand. I might add that if mind is descriptively characterized as unfolding according to kinaesthetic horizonal structures, if mind is not some kind of presence over and above this, then a zombie-body moving according to mindful horizons and temporality is in its very movement already mindful. There is no further sort of thing for a mind to be, no further 'place' in which to find mindalthough there are further developmental layers to bodily mindfulness, and these would be crucial to differences between mindfulness in the broad sense exhibited by animal bodies in general, and its elaboration, through the incorporation of language, tools, and culture, in the phenomena we find, for example, in human minds. The above suggests how movement of the Leib as whole is of itself mindful. This does not amount to behaviourism, for behaviourism claims that mind is nothing other than behaviour conceptualized as something all present. What the above asks us to see is rather that we must not conceptualize behaviour of the Leib as mere changes between states that are all present, but as ontologically escaping presence, via the temporality of behaviour.

Third, from Husserl onward, phenomenologists have long criticized the "theory theory of other minds" (TTM). TTM addresses the Cartesian problem of other minds. If there is nothing mindful about the body itself, and we do not encounter other minds directly but only through the bodies associated with them, how can we know that others around us have minds and are not merely zombies? TTM's answer is this: to explain the behaviour of other bodies, we find we need a theory, one that invokes another mind as a theoretical-explanatory term. We thus encounter other minds through theoretical inferences. Husserl, Merleau-Ponty (1962; 1964), and other phenomenologists argue that we do not have the data necessary for making this sort of inference, and that in any case the 
phenomena testify against TTM. One encounters another not by way of theory, but by a more fundamental, prenoetic "pairing" between one's Leib and another Leib. (CM $\S \S 49-54)$ This counter-claim gains empirical support from developmental psychology and neurology. For example, the discovery of mirror neurons (which activate either when one makes a particular meaningful gesture, say tearing, or sees another doing it) suggests that one relates to others as meaningfully moving bodies who are counterpart to oneself (see Gallagher 2004). But this would mean that the other's body already appears as itself being a phenomenon of mind. And this would make a great deal of evolutionary sense. What we moving animals most need to do is look out for other moving animals as out to get or help us. From an evolutionary and phenomenological perspective, bodies that move in organized ways already appear to us as mindful. We Cartesians can doubt this, but we are sure not to when a zombie-body starts hunting us down with exceptional stealth and cunning.

\section{Conclusion}

Altogether, the phenomena and the imperatives of life testify that cognition is embodied in the strong sense. But we continually do not notice this, or we deflect telltale phenomena, by stepping outside the flow of time and life onto a temporally austere platform through which we hope to secure the fully present terms that would satisfy certain prejudicial presumptions of explanation. Both empirical and phenomenological studies, however, suggest that this step is misguided. We must bring mind back to life, conceive body and mind as two aspects of the same continually developing temporal process.
${ }^{1}$ The degree to which Descartes himself endorses the crypto-Cartesian and Cartesian prejudices here discussed is controversial. I use these terms broadly, to refer to positions derived from or referred to Descartes, whether rightly or wrongly.

2 The deployment of kinaesthesis at this point raises the problem that the concept of kinaesthesis might already depend on a distinction or indistinction between mind and body, such that the overall argumentative strategy is troubled. (My thanks to Daniel Schmicking for pointing out this problem.) We can venture a reply that, descriptively, mind and body appear as relative terms within the more primordial phenomenon of kinaesthesis. We do not find notes of a melody outside of a melody, and vice versa. Similarly, we do not find coherent moments of kinaesthesis outside of their overarching temporal organization, and vice versa. The thought here is that the different temporal moments through which a kinaesthesis unfolds stand as the relative body of this kinaesthesis, and the organizing, temporalizing flow internal to and overarching these moments stands as the relative mindfulness of the kinaesthesis. The moments and their temporalizing, the bodilynesss and the mindfulness, are not two different things, although they are distinguishable. In this view, mindfulness is exposure to time via the bodilyness of movement, but mindfulness is this exposure as a temporalizing that runs through the moments. Pursuit of this point would, though, take another paper.

${ }^{3}$ On this topic and its neglect in the reception of Husserl, see Sheets-Johnstone (1999), Zahavi (1994), Zahavi (2003).

${ }^{4}$ On Leib vs. Körper see Leder (1992). 


\section{References}

Amorim, Michel-Ange, and Brice Isableu. 2006. Embodied Spatial Transformations: "Body Analogy" for the Mental Rotation of Objects. Journal of Experimental Psychology: General 135: 327-347.

Anderson, Michael. 2007. Review of How the Body Shapes the Mind. Philosophical Psychology 20: 127-142.

Barbaras, Renaud. 1992. Motricité et phénoménalité chez le dernier Merleau-Ponty. In MerleauPonty: phénoménologie et expériences, eds. Marc Richir and Etienne Tassin, pp.: Millon.

_. 2003. Life and Perceptual Intentionality. Research in Phenomenology 33: 157-166.

Berthoz, A. 2006. Emotion and Reason: The Cognitive Science of Decision Making. Translated by Giselle Weiss. Oxford: Oxford University Press.

Berthoz, Alain. 2000. The Brain's Sense of Movement. Cambridge, Mass.: Harvard University Press.

Bongard, Josh C., and Chandana Paul. 2000. Investigating Morphological Symmetry and Locomotive Efficiency Using Virtual Embodied Evolution. In From Animals to Animats 6: Proceedings of the Sixth International Conference on Simulation of Adaptive Behavior, eds. Jean-Arcady Meyer, Alain Berthoz, Dario Floreano, Herbert Roitblat and Stewart W. Wilson, pp. 420-429. Cambridge, Mass.: MIT Press.

Borrett, Donald, Sean Kelly, and Hon Kwan. 2000. Phenomenology, Dynamical Neural Networks and Brain Function. Philosophical Psychology 13 (2): 213-228.

Brooks, R. 1991. Intelligence without Representation. Artificial Intelligence: 139-159.

Burwood, Stephen, Paul Gilbert, and Kathleen Lennon. 1999. Philosophy of Mind. Montreal: McGill-Queen's University Press.

Casey, Edward S. 2000. Remembering: A Phenomenological Study. 2nd ed. Bloomington: Indiana University Press.

Churchland, Patricia S., Vilayanur S. Ramachandran, and Terrence J. Sejnowski. 1994. A Critique of Pure Vision. In Large Scale Neuronal Theories of the Brain: Computational Neuroscience, eds. Christof Koch and Joel L. Davis, pp. 23-60. Cambridge, MA: MIT Press.

Clark, Andy. 2001. Reasons, Robots, and the Extended Mind. Mind and Language 16 (2): 121145. . 2006. Material Symbols. Philosophical Psychology 19: 291-307.

Clark, Andy, and David J. Chalmers. 1998. The Extended Mind. Analysis 58: 7-19.

Collins, H.M. 2000. Four Kinds of Knowledge, Two (or Maybe Three) Kinds of Embodiment, and the Question of Artificial Intelligence. In Heidegger, Coping, and Cognitive Science: Essays in Honor of Hubert L. Dreyfus, eds. Mark Wrathall and Jeff Malpas, pp. 179-195. Cambridge, Mass.: MIT Press.

Collins, Steve, Andy Ruina, Russ Tedrake, and Martijn Wisse. 2005. Efficient Bipedal Robots Based on Passive-Dynamic Walkers. Science 307: 1082-1085.

Csepregi, Gabor. 2006. The Clever Body. Calgary: The University of Calgary Press.

Damasio, Antonio R. 1999. The Feeling of What Happens: Body and Emotion in the Making of Consciousness. New York: Harcourt Brace. . 2000. Descartes' Error: Emotion, Reason, and the Human Brain. New York: Quill. . 2003. Looking for Spinoza: Joy, Sorrow, and the Feeling Brain. Orlando, Fla.: Harcourt.

Dewey, John. 1972. The Reflex Arc Concept in Psychology. In John Dewey: The Early Works, 1882-1898, pp. 96-109. Carbondale: Southern Illinois University Press. 
Dickinson, Michael H., Claire T. Farley, Robert J. Full, M. A. R. Koehl, Rodger Kram, and Steven Lehman. 2000. How Animals Move: An Integrative View. Science 288: 100-106.

Djikstra, Katinka, Michael P. Kaschak, and Rolf. A Zwaan. 2007. Body Posture Facilitates Retrieval of Autobiographical Memories. Cognition 102 (139-49).

Dreyfus, Hubert L. 1991. Being-in-the-World: A Commentary on Heidegger's Being and Time, Division I. Cambridge, Mass.: MIT Press.

- 1992. What Computers Still Can't Do: A Critique of Artificial Reason. Cambridge, Mass.: MIT Press.

. 1998. The Current Relevance of Merleau-Ponty's Phenomenology of Embodiment. - 2002. Intelligence Without Representation - Merleau-Ponty's Critique of Mental Representation: The Relevance of Phenomenology to Scientific Explanation. Phenomenology and the Cognitive Sciences 1: 367-383.

- 2007. Why Heideggerian AI Failed and How Fixing it Would Require Making it More Heideggerian. Philosophical Psychology 20 (2): 247-268.

Dreyfus, Hubert L., and Harrison Hall. 1982. Husserl, intentionality, and cognitive science. Cambridge, Mass.: MIT Press/Bradford Books.

Fogel, Alan. 1993. Developing through Relationships: Origins of Communication, Self, and Culture. New York: Harvester Press.

Freeman, Walter J. 1999. How Brains Make Up Their Mind. London: Weidenfeld \& Nicolson. Full, Robert J., and Claire T. Farley. 2000. Musculoskeletal Dynamics in Rhythmic Systems: A Comparative Approach to Legged Locomotion. In Biomechanics and Neural Control of Posture and Movement, eds. Jack M. Winters and Patrick E. Crago, pp. 192-205. New York: Springer Verlag.

Galison, Peter. 1997. Image and Logic: A Material Culture of Microphysics. Chicago: University of Chicago Press.

Gallagher, Shaun. 1986. Body Image and Body Schema: A Conceptual Clarification. Journal of Mind and Behaviour 7: 541-554.

- 1986. Hyletic Experience and the Lived Body. Husserl Studies 3: 131-166.

. 1986. Lived Body and Environment. Research in Phenomenology 16: 139-170.

- 1995. Body Schema and Intentionality. In The Body and the Self, eds. José Luis Bermúdez, Anthony Marcel and Naomi Eilan, pp. 225-244. Cambridge, Massachusetts: MIT Press. 1997. Mutual Enlightenment: Recent Phenomenology in Cognitive Science. Journal of Consciousness Studies 4 (3): 195-214.

—. 2004. Understanding Interpersonal Problems in Autism: Interaction Theory as an Alternative to Theory of Mind. Philosophy, Psychiatry, \& Psychology 11: 199-217. . 2005. How the Body Shapes the Mind. Oxford: Oxford University Press.

- 2007. Review of Mark Rowlands, Body Language: Representation in Action. In Notre Dame Philosophical Reviews.

Gallagher, Shaun, and Anthony J. Marcel. 1999. The Self in Contextualized Action. In Models of the Self, eds. Shaun Gallagher and Jonathan Shear, pp. 273-299. Thorverton, UK: Imprint Academic.

Gibbs, Raymond W. 2006. Embodiment and Cognitive Science. Cambridge: Cambridge University Press.

Gibbs, Raymond W., and Eric A. Berg. 2000. Mental Imagery and Embodied Activity. Journal of Mental Imagery 26: 1-30. 
Groopman, Jerome E. 2007. How Doctors Think. Boston: Houghton Mifflin.

Heidegger, Martin. 1962. Being and Time. Translated by John Macquarrie and Edward Robinson. New York: Harper and Row. Original edition, 1927.

Hurley, S.L. 1998. Consciousness in Action. Cambridge, MA: Harvard University Press.

Husserl, Edmund. 1970. The Crisis of the European Sciences and Transcendental

Phenomenology. Translated by David Carr. Evanston, Illinois: Northwestern University Press.

-1989. Ideas Pertaining to a Pure Phenomenology and to a Phenomenological Philosophy. Second Book: Studies in the Phenomenology of Constitution. Translated by Richard Rojcewicz and André Schuwer. Dordrecht: Kluwer.

—. 1991. Cartesian Meditations. Translated by Dorion Cairns. Dordrecht: Kluwer. Original edition, 1931.

James, William. 1950. The Principles of Psychology. Vol. 1. New York: Dover Publications. Original edition, 1890.

Johnson, Mark. 1987. The Body in the Mind: The Bodily Basis of Meaning, Imagination, and Reason. Chicago: The University of Chicago Press.

- 2007. The Meaning of the Body. Chicago: The University of Chicago Press.

Katz, David. 1989. The World of Touch. Hillsdale, New Jersey: Lawrence Erlbaum.

Kermoian, Rosanne, and Joseph J. Campos. 1988. Locomotor Experience: A Facilitator of Spatial and Cognitive Development. Child Development 59: 908-917.

Kubzansky, Philip E. 1961. The Effects of Reduced Environmental Stimulation on Human Behavior: A Review. In The Manipulation of Human Behavior, eds. Albert D. Biderman and Herbert Zimmer, pp. New York: John Wiley \& Sons.

Lakoff, George, and Mark Johnson. 1999. Philosophy in the Flesh: The Embodied Mind and its Challenge to Western Thought. New York: Basic Books.

Lakoff, George, and Rafael E. Núñez. 2000. Where Mathematics Comes From: How the Embodied Mind Brings Mathematics into Being. New York: Basic Books.

Landgrebe, Ludwig. 1973. The Phenomenological Concept of Experience. Philosophy and Phenomenological Research 34 (1): 1-13.

Leder, Drew. 1990. The Absent Body. Chicago: University of Chicago Press.

- 1992. A Tale of Two Bodies: The Cartesian Corpse and the Lived Body. In The Body in Medical Thought and Practice, ed. Drew Leder, pp. Dordrecht: Kluwer.

Lederman, S.J., and R.L. Klatzky. 1987. Hand Movements: A Window into Haptic Object Recognition. Cognitive Psychology 19: 54-64.

Lee, Ming-Wei, and Julie Gibbons. 2007. Rhythmic Alternation and the Optional Complementiser in English: New Evidence of Phonological Influence on Grammatical Encoding. Cognition 105: 446-456.

Lloyd, Dan Edward. 2004. Radiant Cool: A Novel Theory of Consciousness. Cambridge, Mass.: MIT Press.

McNeill, David. 1992. Hand and Mind: What Gestures Reveal About Thought. Chicago: The University of Chicago Press.

Merleau-Ponty, Maurice. 1962. Phenomenology of Perception. Translated by Colin Smith. Atlantic Highlands, New Jersey: The Humanities Press. Original edition, 1945. . 1964. The Child's Relation with Others. In The Primacy of Perception, ed. James M. Edie, pp. 96-155. Evanston: Northwestern University Press. 
- 1964. The Primacy of Perception and Its Philosophical Consequences. In The Primacy of Perception, pp. 12-42. Evanston, IL: Northwestern University Press.

. 1965. The Structure of Behaviour. Translated by Alden L. Fisher. London: Methuen.

Original edition, 1941.

- 2002. Husserl at the Limits of Phenomenology. Evanston, Illinois: Northwestern University Press.

Noë, Alva. 2004. Action in Perception, Representation and mind. Cambridge, Mass.: MIT Press.

O'Regan, J. Kevin, and Alva Noë. 2001. A Sensorimotor Account of Vision and Visual Consciousness. Behavioral and Brain Sciences 24: 939-1031.

- 2001. What it is Like to See: A Sensorimotor Theory of Perceptual Experience. Synthese 129: 79-103.

Olafson, Frederick A. 1987. Heidegger and the Philosophy of Mind. New Haven: Yale University Press.

Petit, Jean-Luc. 2003. On the Relation Between Recent Neurobiological Data on Perception (and Action) and the Husserlian Theory of Constitution. Phenomenology and the Cognitive Sciences 2: 281-298.

Philips-Silver, Jessica, and Laurel J. Trainor. 2007. Hearing What the Body Feels: Auditory Encoding of Rhythmic Movement. Cognition 105: 533-546.

Roth, Wolff-Michael, and Daniel Lawless. 2002. How Does the Body Get Into the Mind? Human Studies 25: 333-358.

Russon, John. 2003. Human Experience: Philosophy, Neurosis, and the Elements of Everyday Life. Albany: State University of New York Press.

- 2006. On Human Identity: The Intersubjective Path from Body to Mind. Dialogue: Canadian Philosophical Review XLV: 306-314.

Sheets-Johnstone, Maxine. 1990. The Roots of Thinking. Philadelphia: Temple University Press.

- 1999. Phenomenology and Agency: Methodological and Theoretical Issues in Strawson's 'The Self'. In Models of the Self, eds. Shaun Gallagher and Jonathan Shear, pp. 231-252. Thorverton, UK: Imprint Academic.

- 1999. The Primacy of Movement. Amsterdam: John Benjamins Publishing Company.

—. 1999. Re-Thinking Husserl's Fifth Meditation. Philosophy Today SPEP Supplement: 99106.

- 2003. Kinesthetic Memory. Theoria et Historia Scientiarum: International Journal for Interdisciplinary Studies 7: 69-92.

- 2003. Movement: The Generative Source of Spatial Perception and Cognition.

Thelen, Esther. 1984. Learning to Walk: Ecological Demands and Phylogenetic Constraints. Advances in Infancy Research 3: 213-250.

- 1995. Motor Development: A New Synthesis. American Psychologist 50 (2): 79-95.

- 2000. Grounded in the World: Developmental Origins of the Embodied Mind. Infancy 1 (1): 3-28.

Thelen, Esther, and L.B. Smith. 1994. A Dynamic Systems Approach to the Development of Cognition and Action. Edited by Stephen Palmer, MIT Press/Bradford Books Series in Cognitive Psychology. Cambridge, MA: MIT Press/Bradford Books.

Thompson, Evan. 1997. Symbol Grounding: A Bridge from Artificial Life to Artificial Intelligence. Brain and Cognition 34: 48-71.

- 2007. Mind in Life: Biology, Phenomenology, and the Sciences of Mind. Cambridge Mass.: Belknap Press of Harvard University Press. 
Tucker, Don M. 2007. Mind from Body: Experience from Neural Structure. Oxford: Oxford University Press.

Turvey, Michael T. 2007. Action and Perception at the Level of Synergies. Human Movement Science 26: 657-697.

Varela, Francisco J. 1991. Organism: A Meshwork of Selfless Selves. In Organism and the Origins of Self, ed. Alfred I. Tauber, pp. 79-107. Dordrecht, Netherlands: Kluwer. . 1996. Neurophenomenology: A Methodological Remedy for the Hard Problem. Journal of Consciousness Studies 3 (4): 330-349.

— 1999. The Specious Present: A Neurophenomenology of Time Consciousness. In Naturalizing Phenomenology: Issues in Contemporary Phenomenology and Cognitive Science, eds. Jean Petitot, Francisco J. Varela, Bernard Pachoud and Jean-Michel Roy, pp. 266-314. Stanford: Stanford University Press.

Varela, Francisco J., Evan Thompson, and Eleanor Rosch. 1993. The Embodied Mind: Cognitive Science and Human Experience. Cambridge, Mass.: MIT Press.

Wheeler, Michael. 2005. Reconstructing the Cognitive World: The Next Step. Cambridge, Mass.: MIT Press.

Wilson, Margaret. 2002. Six Views of Embodied Cognition. Psychonomic Bulletin and Review 9 (4): 625-636.

Wrathall, Mark, and Jeff Malpas, (eds). 2000. Heidegger, Coping, and Cognitive Science. Cambridge, Mass.: MIT Press.

Zahavi, Dan. 1994. Husserl's Phenomenology of the Body. Etudes Phénoménologique 19: 63-84. . 2003. Husserl's Phenomenology. Stanford, California: Stanford University Press.

Zelazo, P.R. 1983. The Development of Walking: New Findings and Old Assumptions. Journal of Motor Behavior 15: 99-137.

- 1984. Learning to Walk: Recognition of Higher Order Influences. Advances in Infancy Research 3: 251-260. 